\title{
Investigations of impurity gettering in multicrystalline silicon
}

\author{
A.A. Evtukh, V.G. Litovchenko, A.S. Oberemok, V.G. Popov, Yu. V. Rassamakin, \\ B.N. Romanyuk, S.G. Volkov \\ Institute of Semiconductors Physics of NASU, 45, prospect Nauki, 03028, Kyiv, Ukraine
}

\begin{abstract}
The processes of gettering the recombination-active impurities in multicrystalline silicon were investigated using methods of mass spectrometry of neutral atoms with the depth profile analysis and spectroscopy of a surface photovoltage (permitting to determine the diffusion length of nonequilibrium charge carriers). Getters formed by a silicon layer with a developed internal surface, and also combined getter (the mentioned layer covered with a thin film of aluminum) were used. It was shown that the efficiency of gettering depends on annealing temperature and character of Al depth distribution that, in turn, depends on the regimes of structurally modified silicon layer formation. The models of gettering that enabled us to explain obtained results are considered.
\end{abstract}

Keywords: multicrystalline silicon, solar cells, gettering, diffusion length, mass-spectrometry.

Paper received 02.10.01; revised manuscript received 28.11.01; accepted for publication 12.12.01.

\section{Introduction}

Large-grained crystalline silicon (multicrystalline $\mathrm{Si}, \mathrm{mc}-$ $\mathrm{Si}$ ) is widely used for manufacturing the photovoltaic solar energy converters, as it is much cheaper than monocrystalline Si and allows to make solar cells (SCs) and batteries with high enough efficiency (up to $15 \ldots 17 \%$ ). The SCs' efficiency in many aspects is determined by a lifetime of non-equilibrium charge carriers. It is known that impurities of metals that are present in a silicon material due to both contamination during crystal growing, and during technological process of SC manufacturing essentially reduce a lifetime of charge carriers. Such recombination-active impurities as $\mathrm{Fe}, \mathrm{Cu}, \mathrm{Cr}, \mathrm{Ni}, \mathrm{Au}, \mathrm{Ti}$ and some other contribute to a degradation of SC efficiency starting from concentrations about $10^{13} \ldots 10^{15} \mathrm{~cm}^{-3}$.

For lowering the impurity content methods of gettering are widely used. In one of the spread variants, the getter layer characterized by a high solubility of impurities is superimposed on the backside of a semiconductor wafer. The subsequent annealing of wafer with a getter ensures diffusion of impurities from the silicon bulk to a getter region.
The features of gettering in mc-Si are connected with the presence of grain boundaries that can trap impurities, in such manner impeding their gettering. On the other hand, grain boundaries may promote the penetration of hydrogen and some other impurities passivating the recombination-active centers.

In modern technologies of the mc-Si - based SC manufacturing, a number of gettering methods is used. For example, it is the high-dose implantation of $\mathrm{H}^{+}$or $\mathrm{He}^{+}$ions, deposition of Al films; gettering by a layer strongly doped with phosphorus, etc. [1-4].

The effective getter used for gettering in $\mathrm{mc}-\mathrm{Si}$ is porous $\mathrm{Si}[5,6]$. However, a drawback of this gettering method is the propensity of porous $\mathrm{Si}$ actively absorb impurities from an ambient during annealing. For example, according to the data [8], even such a slowly diffusing impurity as arsenic $\left(\mathrm{D}_{\mathrm{As}} \sim 10^{-15} \mathrm{~cm}^{2} / \mathrm{s}\right.$ at $T=1000^{\circ} \mathrm{C}$, [7]) at photon annealing within 1 second $\left(T \sim 1000{ }^{\circ} \mathrm{C}\right)$ is found to be uniformly distributed in a $1.5 \mu \mathrm{m}$-thick porous $\mathrm{Si}$ layer, and, at increase of annealing time to 10 seconds, the $0.2 \mu \mathrm{m}$-thick underlying region of crystalline $\mathrm{Si}$ is doped with As. Such effects lead to additional contaminations, when making thermal operations in insufficiently pure conditions. 


\section{A. A. Evtukh et al.: Investigations of impurity gettering ...}

Use of aluminum film on a back surface of a mc-Si wafer allows to combine gettering process with deriving the back isotype potential barrier [9].

In this paper the investigations of gettering processes are carried out for a combined getter, including a layer of silicon with a developed surface, and a top Al film [10]. Such type of structures was used earlier for gettering monocrystalline and multicrystalline $\mathrm{Si}$ [11, 12], but was not studied in detail. The method of mass spectrometry of neutral atoms is used for the level-by-level impurity analysis of the getter area. It is shown that gettering efficiency depends on annealing temperature and shape of the Al depth distribution, which, in turn, depends on the regime of preparation of structurally modified silicon layer. The models of gettering that permits to explain obtained results are considered.

\section{Experiment}

The mc-Si p-type samples (specific resistance $\sim 1.4 \mathrm{Ohm} \cdot \mathrm{cm}$ ) received from the two suppliers (Zaporozhye Titanium \& Magnesium Industrial Complex (ZTMC), Ukraine, and Bayer Solar GmbH, Germany) have been investigated. The medium sizes of crystal grains were in the interval of 1 to $15 \mu \mathrm{m}$.

Measurements of a diffusion length of minority nonequilibrium charge carriers $L_{d}$ were made by a method of spectral dependence of surface photovoltage. [13]. The measurements of $L_{d}$ values were performed on different sites of a surface to determine of average value and its straggling on a wafer to reduce an error in determination of $L_{d}$ changes after thermal and getter treatments.

The backside of mc-Si wafers were etched in $\mathrm{HF}: \mathrm{HNO}_{3}: \mathrm{H}_{2} \mathrm{O}$ solutions to prepare a layer with a developed internal surface. 2 modes of etching distinguished by a relation of indicated ingredients and time were used. The thickness of the chemically modified layer was determined by a profilometry method and in the both modes was approximately $0.5 \mu \mathrm{m}$. Effective density of a modified layer was measured by a method of gravimetry and for the first mode reached $45 \%$, and for the second one up to $31 \%$ of the density of crystalline $\mathrm{Si}$.

After etching Si, the Al film with the thickness of $\sim 0.3$ $\mu \mathrm{m}$ was deposited on this surface by magnetron sputter- ing. Annealings were made in an argon atmosphere in the temperature range of 550 to $850^{\circ} \mathrm{C}$ during $30 \mathrm{~min}$ utes. As it is shown in [10-12], the gettering effect is displayed just in this temperature interval. After annealing measurements of the $L_{d}$ parameter were made.

The allocation of the recombination-active impurities in getter area was measured by a method of mass spectrometry of neutral atoms using the INA-3 installation (Leybold) when sputtering of the surface in Ar plasma. Thickness distributions of Al before annealings were also measured. The calibration by depth was made by measuring depth of a crater (after ion etching) using a DEKTAK-3030 profiler.

For an estimation of concentration of foreign impurities that accumulate in a getter region the mass spectra at different depths were measured, in accordance with a sputtering of a sample surface. The complexity in identification of impurities is connected with overlapping of signals from isotopes of different elements. For example, the signal from ${ }^{56} \mathrm{Fe}$ isotope is overlapped by a signal from ${ }^{28} \mathrm{Si}_{2}$. In this case for an estimation of iron concentration the signal from ${ }^{54} \mathrm{Fe}$ isotope was used. A procedure of spectra handling including subtraction of ${ }^{28} \mathrm{Si}_{2}$ signal (from a reference sample) from the total signal shaped by Si matrix with Fe impurity was also used. The estimation of $\mathrm{Ti}, \mathrm{Cr}, \mathrm{Mn}, \mathrm{Co}, \mathrm{Ni}$ and $\mathrm{Cu}$ impurity concentration was made using signals from different isotopes that are not overlapped with other elements.

\section{Results}

In Table 1 parameters of the investigated samples before and after annealing at different temperatures are given. As one can see from the Table, $L_{d}$ values for initial samples lay in interval of 47 to $80 \mu \mathrm{m}$. The gettering effect was observed for samples B12, P35 (etching mode №2) after annealing. Absence of an $\mathrm{Al}$ film (sample $\mathrm{P} 34$ ) results in some diminution of $L_{d}$. At the temperature of $550^{\circ} \mathrm{C}$ (for Bayer Solar samples) and $800 \ldots 850^{\circ} \mathrm{C}$ (for all the samples) gettering is not observed. The essential decrease of $\mathrm{L}_{\mathrm{d}}$ is observed for B9 sample (etching mode №1).

In Fig. 1, the depth profiles of Si and different metal atoms in a getter region for a sample without an $\mathrm{Al}$ film (P34) are given. It is clear that the near-surface area of sili-

Table 1. The characteristics and regimes of treatments of the investigated samples

\begin{tabular}{llllll}
\hline \hline Sample number & 3 & $\mathrm{~B} 9$ & $\mathrm{~B} 12$ & P34 & P35 \\
\hline Producer & ZTMC & Bayer & Bayer & ZTMC & ZTMC \\
\hline Type of the structure & $\begin{array}{l}\text { Chemically } \\
\text { modified } \mathrm{Si}+\mathrm{Al}\end{array}$ & $\begin{array}{l}\text { Chemically } \\
\text { modified } \mathrm{Si}+\mathrm{Al}\end{array}$ & $\begin{array}{l}\text { Chemically } \\
\text { modified } \mathrm{Si}+\mathrm{Al}\end{array}$ & $\begin{array}{l}\text { Chemically } \\
\text { modified Si }\end{array}$ & $\begin{array}{l}\text { Chemically } \\
\text { modified Si+Al }\end{array}$ \\
\hline $\begin{array}{l}\text { Thickness of chemically- } \\
\text { modified layer/Regime of etching }\end{array}$ & $0.3 / 1$ & $0.3 / 1$ & $0.3 / 2$ & $0.3 / 2$ & $0.3 / 2$ \\
\hline Annealing temperature, ${ }^{\circ} \mathrm{C}$ & 800 & 750 & 750 & 550 & 550 \\
\hline$L_{d}$ before annealing, $\mu \mathrm{m}$ & 80 & 47 & 63 & 70 & 80 \\
\hline$L_{d}$ after annealing, $\mu \mathrm{m}$ & 80 & 33 & 134 & 67 & 131 \\
\hline \hline
\end{tabular}




\section{A. A. Evtukh et al.: Investigations of impurity gettering ...}

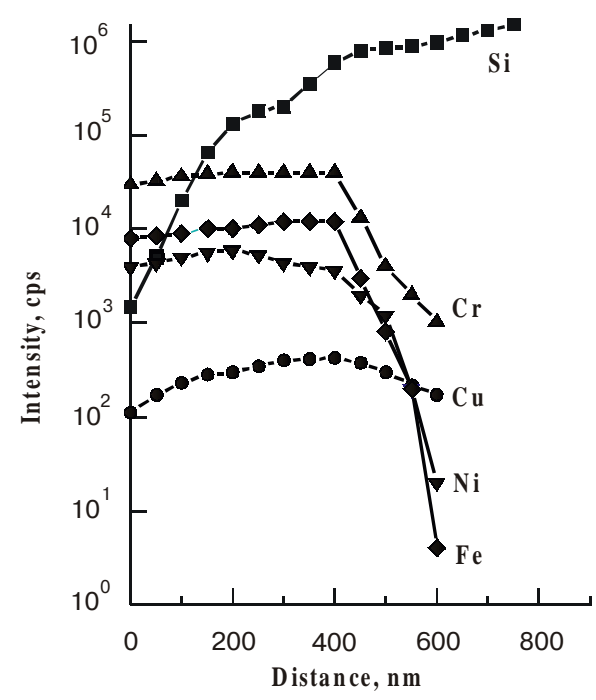

Fig. 1. Impurity depth profiles in getter region of the P34 sample.

con, subjected to etching, is strongly polluted with different metal impurities with concentrations of $10^{17}$ to $5 \cdot 10^{19}$ $\mathrm{cm}^{-3}$. The concentrations of $\mathrm{Cr}, \mathrm{Fe}$ and $\mathrm{Ni}$ are especially high. It is characteristic that before annealing these impurities were not observed.

The impurity concentrations diminish in accordance with ion sputtering of surface layer. At the presence of $\mathrm{Al}$ film such amounts of impurities after annealing are not detected for none sample. For a sample P35 Cr, Cu and Ni impurities are detected. In Fig. 2 the depth profile of copper atoms near the backside of this sample is given. There are two reference areas of $\mathrm{Cu}$ allocation: on the depth of 0 to 0.3 $\mu \mathrm{m}$, which corresponds to the thickness of Al film, and 0.3 to $0.8 \mu \mathrm{m}$ (the area, modified by the chemical etching). The maximum copper concentration in getter region is of $2 \cdot 10^{18}$ $\mathrm{cm}^{-3}$. If we suppose that there was a gettering of copper from all the sample thickness $(\sim 300 \mu \mathrm{m})$, the medium $\mathrm{Cu}$ concentration in a sample before gettering makes $\sim 3 \cdot 10^{15}$ $\mathrm{cm}^{-3}$. For $\mathrm{Cr}$ and $\mathrm{Ni}$ the thickness distributions have a quali-

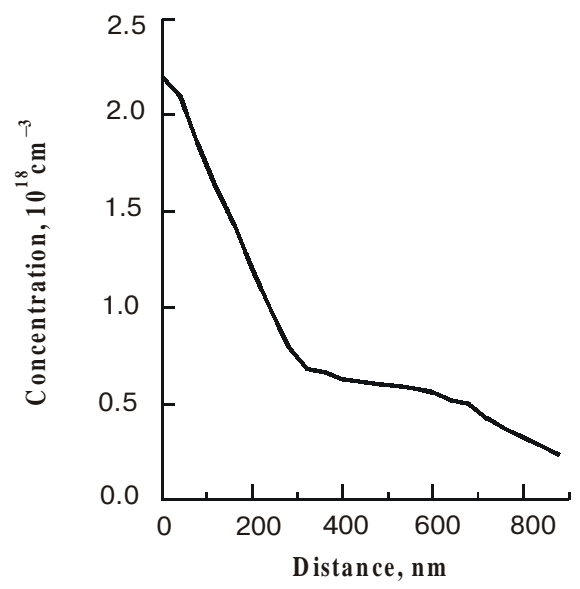

Fig. 2. Copper concentration depth profile in getter region of the P35 sample. tatively same form, but the concentrations of these impurities are 2 times less.

We have measured the thickness distributions of $\mathrm{Al}$ after annealing at different times and estimated the diffusion constant of aluminum in a chemically modified Si layer. At the temperature of $800^{\circ} \mathrm{C}$ we obtained $\mathrm{D}_{\mathrm{Al}} \sim 3 \cdot 10^{-13} \mathrm{~cm}^{2} / \mathrm{s}$, which by 3 orders exceeds the similar value for monocrystalline silicon [7].

In Fig. 3 thickness distributions of $\mathrm{Al}$ and $\mathrm{Si}$ for the two samples (B9, B12), annealed at the temperature of $750^{\circ} \mathrm{C}$ and distinguished by a mode of chemical etching are given. These samples, as it was marked above, differ by efficiency of gettering: in the $\mathrm{B} 9$ sample the gettering effect misses, whereas in the $\mathrm{B} 12$ sample the $\mathrm{L}_{\mathrm{d}}$ parameter after gettering is increased up to $80 \%$.

As it is obvious from this figure, thickness distribution of both $\mathrm{Al}$, and $\mathrm{Si}$ for indicated samples essentially differ. For the sample B12 (Fig. 3a), a practically stoichiometrical $\mathrm{Al}$ film on the surface is observed, with the subsequent tailing of distribution by the depth of $\sim 800 \mathrm{~nm}$, and the sharp increase of Si concentration with depth, so Si concentration is saturated at $300 \mathrm{~nm}$. In the sample B9 (Fig. 3b) the structure of getter region is quite another. The area up to depths of $300 \mathrm{~nm}$ is characterized by smoothly varying increase of Si concentration, that is saturated at the depth of $\sim 600 \mathrm{~nm}$. The $\mathrm{Al}$ concentration in the region of 0 to 300 $\mathrm{nm}$ is much lower, than in the sample B12. The considerable fraction of $\mathrm{Al}$ in this region is in oxidized state, it is indicated by high concentration of oxygen and $\mathrm{AlO}$ phase. The depth of Al penetration into Si also is much higher than in the sample B12. The shape of Al distribution looks like a curve with a maximum. Thus, there is a direct correlation between gettering efficiency and the structure of the getter area.

\section{Discussion}

As it is known from the literature [5-7], effective impurity gettering is possible at developed internal surface formation by chemical etching of $\mathrm{Si}$, but thus the annealing should be made in pure ambient, as chemically modified layer actively absorbs impurities from a surrounding medium. The results obtained for the sample P34 that displays no $L_{d}$ increase and accumulation of impurities in the near-surface modified region that is simultaneously observed (Fig. 1) confirm it.

In Fig. 4, the diagrams of possible processes occurring at gettering with the use chemically modified layer (a) and its combination with aluminum film $(b, c)$ are given. Si layer with a developed surface operates as an effective getter of impurities from the bulk of a wafer, however at annealing in insufficiently pure conditions it will be saturated with impurities from a surrounding medium, oxidized, and in the case of annealing temperature increase $\left(>800^{\circ} \mathrm{C}\right)$ is a source of impurities itself. These impurities will diffuse to the sample volume. Gettering efficiency in this case is minimum that is confirmed by the described experiments.

At presence of the $\mathrm{Al}$ film, the annealing results in growth of $\mathrm{Al}_{2} \mathrm{O}_{3}$ thin surface film that protects a getter layer 


\section{A. A. Evtukh et al.: Investigations of impurity gettering ...}

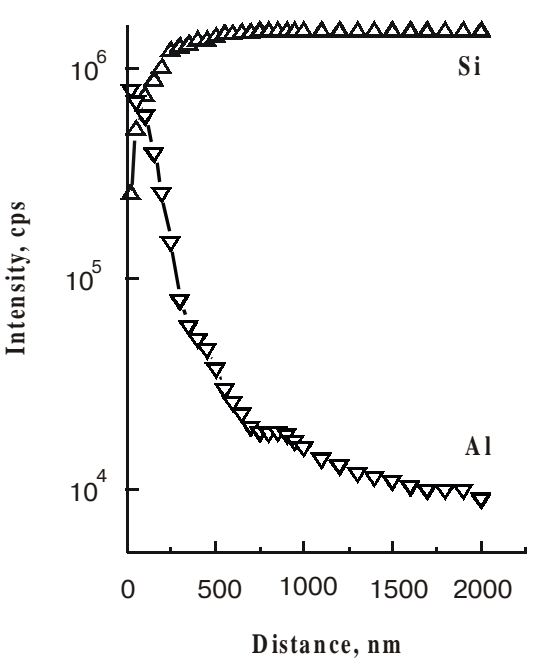

a)

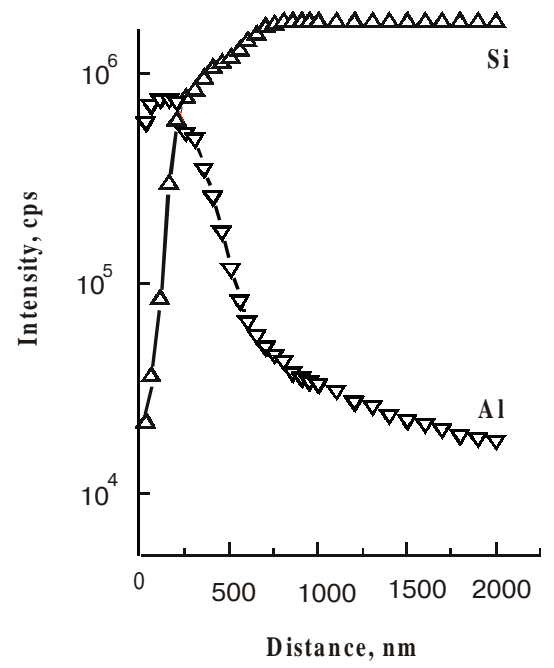

b)

Fig. 3. Si and $\mathrm{Al}$ depth profiles in getter regions of the B12 (a) and B9 (b) samples.

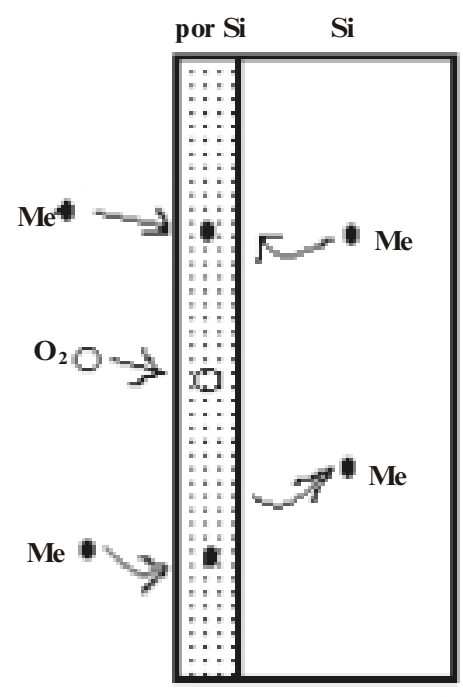

a)

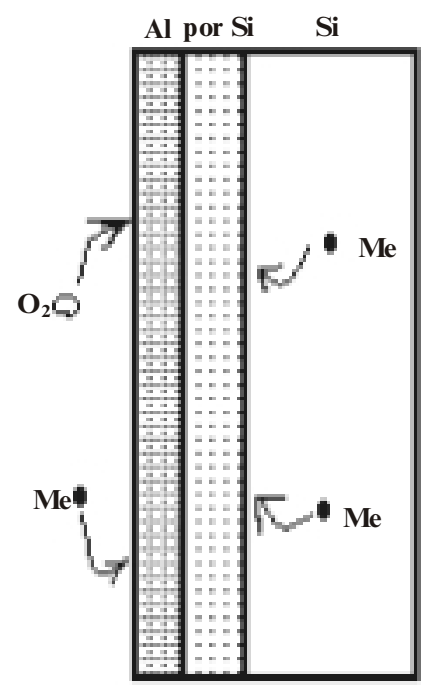

b)

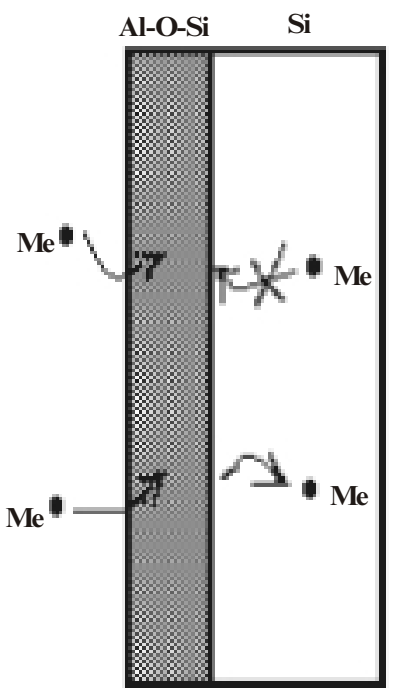

c)

Fig. 4. Diagram of possible processes of impurity diffusion and trapping at gettering by Si layer with a developed surface (a) and by this layer with $\mathrm{Al}$ film in the cases of smaller (b) and larger (c) effective density of the chemically modified layer.

from penetration of impurities from atmosphere of the furnace. In this case, the chemically modified layer and aluminum film operate as effective getter of impurities from the sample bulk. The depth distribution of copper in getter layer displays that its greatest amount is accumulated in the Al film, and about 10\% - in the layer of Si with developed inner surface, where the aluminum content is small. The increase of annealing temperature results in intensive dissolution of aluminum in the chemically modified layer and its partial oxidizing. Thus, the efficiency of the getter decreases sharply.

At etching of $\mathrm{Si}$ in the regime №2 (smaller effective density of a modified layer) at annealing the melted aluminum will rapidly moisten the near-surface region of a modified layer, passivating it from action of exterior contaminations, and then partially penetrates deeply into the sample with formation of Si-Al eutectics, ensuring gettering effect. In the case when effective density of etched layer increases (regime №1), at the same annealing temperature, aluminum penetrates into chemically modified layer more slowly, it simultaneously interacts with oxygen and other impurities present both in the atmosphere of the furnace and in the layer with a developed surface. As our mass-spectrometer analysis displays (Fig. 3), such modifications of structure and composition of getter layer results in the change of mechanisms of aluminum penetration into the sample. In this case, the getter region consists of an intermixture of aluminum, oxygen, silicon and their compounds, and gettering effect does not take place. 


\section{A. A. Evtukh et al.: Investigations of impurity gettering ...}

\section{Acknowledgments}

This work was partly supported by the STCU project \#U-031.

\section{References}

1. E. R. Weber, S. A. McHugo, H. Hieslmair, Gettering of transition metals in multicrystalline silicon for photovoltaic applications // Solid State Phenomena, 47-48, p.p. 165 - 170, (1996)

2. N. Gayhenquet, S. Martinuzzi, Efficiency of nanocavity backside gettering in multicrystalline silicon wafers // Proc. 2nd World Conf. on Photovoltaic Solar Energy Conversion. 6 - 10 July 1998, Vienna, Austria., p.p. 1599 - 1602

3. W. Jooss, G. Hahn, P. Fath et al., Improvement of diffusion lengths in multicrystalline Si by P-Al co-gettering during solar cell processing // Ibid, p.p. 1689 - 1692

4. S. Ostapenko, L. Jastrzebski, B. Sopori, Change of minority carrier diffusion length in polycrystalline silicon by ultrasound treatment // Semicond. Sci. Technol., 10 (8), p.p. 1494 - 1500, (1995)

5. P. Menna, Y. S. Tsuo, M. M. Al-Jassim et al., Purification of metallurgical-grade silicon by porous-silicon etching // Proc. 2nd World Conf. on Photovoltaic Solar Energy Conversion. 6 10 July 1998, Vienna, Austria, p.p. 1232 - 1235

6. L. Schirone, G. Sotgiu, M. Montecchi, G. Righini, R. Zanoni, Stain etched porous silicon technology for large area solar cells
I/ Proc. 2nd World Conf. on Photovoltaic Solar Energy Conversion. 6 - 10 July 1998, Vienna, Austria, p.p. 276 - 279

7. S. M. Sze, Physics of semiconductor devices, A Wiley-Interscience Publ., N.Y., 1981.

8. V. P. Bondarenko, V. T. Borisenko, V. A. Labunov, Diffusion of arsenic through porous silicon at second thermo-treatment by non-coherent light // Semiconductors, 20 (5), p.p. 929 - 933 (1986)

9. V. G. Popov, Solar cells based on multicrystalline silicon // Semiconductor Physics, Quantum Electronics \& Optoelectronics, 3 (4), p.p. $479-488$ (2000)

10. V. G. Litovchenko, N. I. Klyui, A. A. Evtukch, et al., New gettering procedures for fabrication of solar cells with improved parameters // Proc. 7th Arab Int. Solar Energy Conf \& Regional World Renewable Energy Congress, 19 - 22 Febr., 2001, Sharjah, UAE, Book of Abstracts, p.p. $305-306$

11. A. A. Efremov, N. I. Klyui, V. G. Litovchenko, et al, Development of gettering processes for the preparation of the solar silicon material // Proc European Conf. on Photovoltaics \& JOULE PV III Contractors' Meeting, 25 - 27 Oct., 1999, Krakow, Poland. Abstracts, p. 24

12. V. G. Litovchenko, N. I. Klyui, A. A. Evtukh, et al., Solar cells prepared on multicrystalline silicon subjected to new gettering and passivation treatments // EMRS-2001 Spring Meeting, June 5 - 8, 2001, Strasbourg, France. Final Book of Abstracts, p. E19.

13. Standard Test Methods for Minority Carrier Diffusion Length in Extrinsic Semiconductors by Measurements of Steady-State Surface Photovoltage. ASTM Designation: F391-96, published: April 1996 // Annual Book of ASTM Standards, v. 10.05 (Electronics II), p.p. $150-158$. 